\title{
Distributing Feedback Wisely to Empower Girls in STEM
}

\author{
Manuela Paechter ${ }^{1 *}$, Silke Luttenberger ${ }^{2}$ and Bernhard Ertl ${ }^{3}$ \\ ${ }^{1}$ Educational Psychology, Institute of Psychology, University of Graz, Graz, Austria, ${ }^{2}$ University College of Teacher Education \\ Styria, Institute for Early Childhood and Primary Teacher Education, Graz, Austria, ${ }^{3}$ Learning and Teaching With Media, \\ Department of Education, Universität der Bundeswehr München, Neubiberg, Germany
}

Keywords: girls in STEM, feedback, growth mindset, self-efficacy, outcome expectations, interest, gender stereotypes

\section{SELF-EFFICACY, OUTCOME EXPECTATIONS, AND INTEREST AS KEY VARIABLES FOR THE FORMATION OF STEM ASPIRATIONS}

For decades, only one-fourth of women have comprised the total number of people in STEM professions in the EU. This is an alarmingly low number. With labor markets continuing to communicate an increasing need in STEM workforces, this low number signals unfulfilled talent that is otherwise greatly needed in many critical fields. There are a number of situations where girls and women stumble along the path to a STEM career. Some of these occur in the formative years of primary and secondary education, during which time a majority of girls feel (and are in fact) estranged from STEM subjects. Experiences in school and in the classroom appear to reinforce these experiences instead of preventing them.

The development of academic aspirations in STEM, and promoting the desire to have a career in STEM can be understood as a long-term developmental process in which decisions are formed via the interaction of personal characteristics along with environmental structural and social factors like educational institutions, school, teachers, family etc. (Watt et al., 2006; Lent and Brown, 2019; Turner et al., 2019).

STEM self-efficacy, STEM outcome expectations, and interest are key variables for a choice of academic and vocational STEM courses and careers over the course of education and working life (see Figure 1). Self-efficacy in STEM describes an individual's belief about his or her capability to manage and solve tasks. Outcome expectations are personal beliefs about the consequences of task-specific behavior. They include experiences and what people think and expect about extrinsic and intrinsic reinforcements, for example external rewards like good grades; experiencing internal, self-directed consequences like being proud of an accomplishment; or even being fully absorbed in a task. Self-efficacy beliefs and outcome expectations are important for the formation of interest in an academic field. Individuals develop interest in fields or activities when they feel competent and anticipate that their performance will yield favorable outcomes (Lent and Brown, 2019). STEM self-efficacy, outcome expectations, and interest are crucial for the formation of goals in STEM, for example the intention to enroll in a course, to pursue an academic major or to attain a certain level of performance. Favorable, yet realistic self-efficacy, positive outcome expectations, and interest in a field help individuals to make the best possible use of their potential.

Girls can be regarded as an at-risk group when it comes to self-efficacy, positive outcome expectations, and interest in STEM fields. They are more likely than boys to attribute failure in STEM to a lack of their own ability. Over the course of childhood and adolescence, self-depreciatory assessment and pessimistic outcome expectations lead to avoidance of STEM, unhelpful learning behaviors, lower performance, and less interest in STEM (Ertl et al., 2017; Luttenberger et al., 2018). So it is not surprising that girls shy away from STEM (OECD, 2015), especially in light of the fact that school and learning experiences 


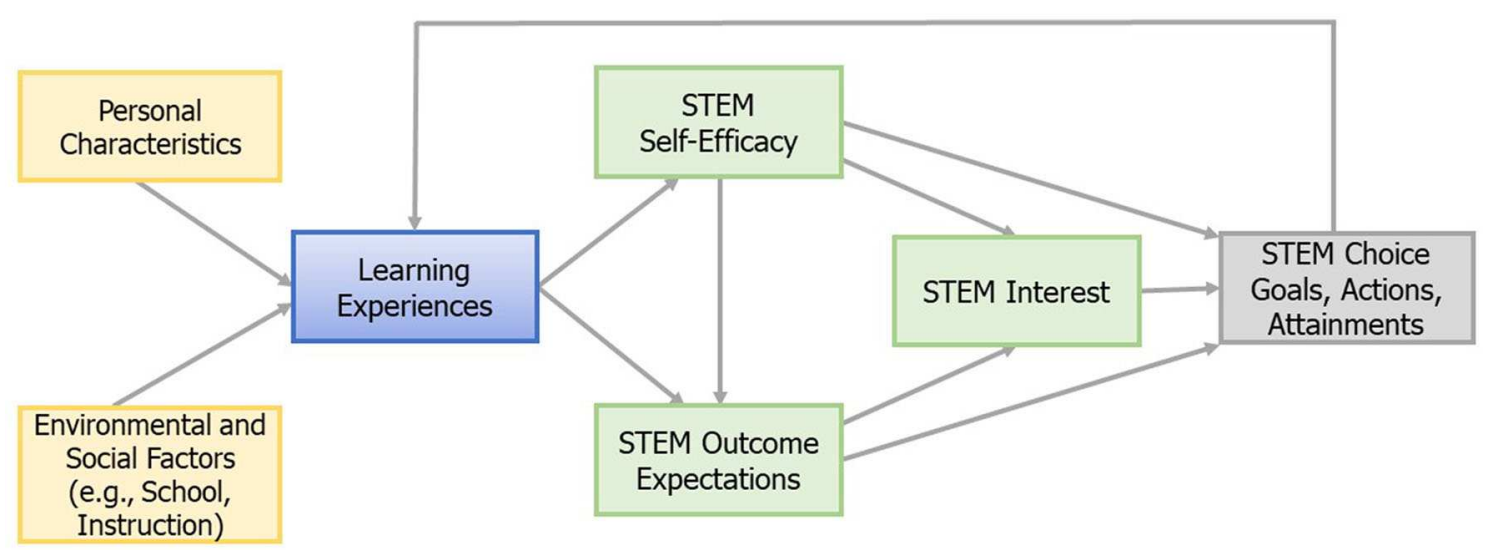

FIGURE 1 | Self-efficacy, outcome expectations, interest as key variables for formation of STEM aspirations.

often contribute to this. The present article, therefore, discusses the impact of learning experiences for empowering girls in STEM courses. Teacher feedback plays an important role in this process, and thus different types of feedback and their possible influence on students' learning will be discussed.

\section{IMPORTANCE OF LEARNING EXPERIENCES}

Learning experiences in school and other social contexts are the main source of self-efficacy development and outcome expectations. Teachers, parents, and other significant persons influence children in their beliefs about and attitudes toward STEM. By choosing adequate instructional strategies, selecting appealing learning content, and interacting with students, teachers may enhance feelings of self-efficacy, provide for positive outcome expectations, and promote interest in STEM for both boys and girls. Teacher feedback is particularly influential when it comes to girls' beliefs about and attitudes toward STEM (She, 2000).

Girls rely more on teacher feedback than boys to assess their performance in STEM. Even high-performing girls rely less on their grades as an indicator of their knowledge, and look to their teacher instead (Skipper and Leman, 2017). Their critical self-assessments are often accompanied by their belief that talent is the main requirement for success in STEM; moreover, these negative self-assessments can be intensified by gender stereotypes that attribute STEM talent exclusively to boys/men (Luttenberger et al., 2018).

In light of these disadvantages, it would appear even more important for teachers to empower girls in the classroom. However, research shows that teacher feedback often fails to support girls in STEM. Girls receive less instructional and discussion time in the STEM classroom than boys, and are less often the focus of classroom interaction, receiving less feedback (Skipper and Leman, 2017). Teachers also often attribute boys' STEM achievement to talent and girls' STEM achievement to effort and hard work (Burnett, 2002), conveying the message that
STEM subjects are not for everyone. When teachers themselves hold gender stereotypes, they may communicate discouraging messages about STEM without even being aware of doing so, or without recognizing that their attitudes might be biased (Smith et al., 2012).

\section{FEEDBACK THAT EMPOWERS GIRLS' MINDSETS}

Feedback can focus either on the person or on learning processes and learning behaviors as a source of achievement. Personrelated feedback refers to a learner's unchangeable characteristics (for example "you are talented in mathematics") and supports the development of a so-called fixed mindset. Learners with a fixed mindset assume that ability, talent, and intelligence within a person are pre-determined and cannot be changed (Dweck, 2007). Consequently, the self-efficacy of these learners is tied to their assessments of their assumed stable personal characteristics.

Mindsets may change depending on academic domains; a person may hold different mindset beliefs in different areas. Furthermore, in the overall population of students, specific domains are associated with success requiring either talent or hard work. Students are particularly likely to see physics and mathematics as subjects in which success depends on innate ability (Aguilar et al., 2014). With girls in particular, STEM mindset beliefs are often intertwined with stereotypes about female inferiority (Ertl et al., 2017; Luttenberger et al., 2019). When students with a fixed mindset encounter a difficult problem or concept, they see these difficulties mainly as expectable evidence of their lack of innate ability. They tend to seek out easy problems (to prove their ability) and avoid challenging ones that would help them progress in their learning (Dweck, 2007; Skipper and Leman, 2017). As Freudenthaler et al. (2008) could show, task avoidance is an important predictor for girls' school achievements.

In contrast, process-related feedback focuses on learning processes, effort, and the way a person approaches a task (examples would be "you tried hard at this" or "you found the 
right strategy to approach this task") (Harks et al., 2014). It supports development of a growth mindset, i.e., the belief that talent and ability are malleable and can be improved (Dweck, 2007). Learners with a growth mindset assume that they may influence their learning achievements via effort and adequate learning strategies.

Process-related feedback has advantages over person-related feedback. It provides encouragement and informs about concrete strategies and behaviors for improvement (Dweck, 2007). Process-related feedback is especially efficient when it informs beyond the adequateness of learning results and also provides information about the adequateness of the learning processes. In a study on logical mathematic-related tasks, process-related feedback had implications on children's choices of future tasks and their outcome expectations. Children who had received feedback on the adequateness of their effort were more likely to choose tasks that point to mastery goal orientations and intrinsic rewards (for example, they chose "problems that I'll learn a lot from, even if I won't look so smart"; Mueller and Dweck, 1998, p. 36) whereas children who had received personrelated feedback chose tasks that pointed to performance goal orientation (for example, they chose "problems that aren't too hard, so I don't get many wrong," Mueller and Dweck, 1998, p. 36). These feedback effects can already be observed in younger children. In two investigations with 5 to 6 year old children, those who received person-related feedback (expressed as comment of a fictitious teacher's pride of or disappointment in a pupil) were more likely to assume that already a single mistake points at stable learning deficits than children who received processrelated feedback (expressed as pointing out correct or incorrect solutions, comments on effort). Children in the process-related feedback group also expressed higher motivation and showed more persistence (Kamins and Dweck, 1999).

Process-related feedback and the attribution of success to effort and own learning behavior is also related to higher levels of task persistence, their enjoyment, and interest in them. Learners who attribute success to their learning behaviors and effort also compare their task outcomes less to the outcomes of other learners (Mueller and Dweck, 1998).

However, despite these advantages of process-related feedback, it seems that girls do not always benefit from it in STEM classrooms, especially when they maintain a fixed STEM mindset that is intertwined with gender stereotypes. And not only girls with lower or medium abilities, but even girls with high abilities and interest are susceptible to stereotypes against women in STEM (Ertl et al., 2017).

In a study with students in secondary education (Skipper and Leman, 2017), process-related feedback failed to raise the attractiveness of possible STEM careers (feedback indicated either that students would be suited to take a STEM course because they work hard vs. or because they are clever). Here, person-related feedback was more successful; it suited students' prior assumptions that success in science is mainly due to innate ability. Correspondingly, person-related feedback emphasizing students' high ability levels was more efficient for attracting students to a STEM career than feedback interventions that attributed success in STEM tasks to learning processes and effort. Especially girls are doubtful of their self-efficacy in STEM and rely on interactions with teachers and on their assessments of their ability (Zeldin et al., 2008). Studies on mathematics show that such doubts of self-efficacy and abilities are connected to avoidance of math and science courses (Ashcraft and Moore, 2009). Forsythe and Johnson (2017) point at the important role of the interaction between students' already existing mindsets and feedback; their studies suggest that educators should not only prefer process-related feedback but also take into consideration that they have to change students' negative fixed mindset and beliefs of assumed inferior stable ability levels.

These results emphasize how STEM educators face conflicting effects of the two types of feedback. Person-related feedback has undesirable long-term effects, especially in case of failure, for example in how it decreases the likelihood to choose challenging and difficult tasks and ties self-efficacy assessments to estimation of talent. However, with a fixed and gender-biased mindset, girls may misinterpret the usually more favorable process-related feedback and believe that a teacher is actually pointing out their lack of talent whenever she/he praises their learning behavior and efforts (Skipper and Leman, 2017).

Taken together, the studies discussed here would recommend a combination of person-related and process-related feedback in STEM classrooms, applying each for different purposes. Personrelated feedback is especially important for countering girls' stereotyped beliefs about their lack of talent. Teachers can use person-related feedback (on talent, ability, or pointing out role models similar to the person) to build up their female students' confidence especially of those students who believe that as girls they "are not cut out" for STEM fields (Luttenberger et al., 2018).

It however needs to be complemented by process-related feedback which focuses on learning processes and effort. With its focus on effort and learning processes, process-related feedback delivers its message without singling out specific personal learner characteristics like gender, talent etc. This feedback is needed to build up self-efficacy beliefs that success in STEM is based on effort and effective learning strategies. It serves to provide for positive outcome expectations where task fulfillment is experienced as rewarding and self-induced; and it, therefore, supports the development of interest in a field in form of positive attitudes and experiences when being engaged with learning contents. As this type of feedback is related to persistence, motivation and effort it has positive long-term effects, making it very useful for empowering girls in STEM.

\section{CONCLUSIONS AND NEED FOR FURTHER RESEARCH}

This discussion of feedback points at a problem that has rarely been considered in research on learning and instruction. Studies on teacher feedback mostly focus on the beneficial effects of process-related feedback and the support of a growth mindset, while studies on gender stereotypes in STEM mostly focus on how girls' stereotypes can be eliminated, even though these approaches ignore the undesirable effects of person-related feedback. Results of the studies on teacher feedback often can be explained by the use of tasks in neutral or new knowledge domains. However, when students (in STEM mostly girls) already 
carry negative mindsets of their abilities, process-related feedback may lead to different results. Very few studies have considered this special situation that process-related feedback for girls in STEM fails in achieving its positive effects when encountering stereotyped, fixed mindset beliefs (an exception is the study by Skipper and Leman, 2017).

Therefore, the present article intends to point out the conflicting effects of feedback, it attempts to give first recommendations for teachers. However, most importantly it points out that the orchestration of person- and processrelated feedback in STEM classrooms will require more detailed investigation.

\section{REFERENCES}

Aguilar, L., Walton, G., and Wieman, C. (2014). Psychological insights for improved physics teaching. Phys. Today 67, 43-49. doi: 10.1063/PT.3.2383

Ashcraft, M. H., and Moore, A. M. (2009). Mathematics anxiety and the affective drop in performance. J. Psychoeduc. Assess. 27, 197-205. doi: $10.1177 / 0734282908330580$

Burnett, P. C. (2002). Teacher praise and feedback and students' perceptions of the classroom environment. Educ. Psychol. 22, 5-16. doi: 10.1080/01443410120101215

Dweck, C. S. (2007). The secret to raising smart kids. Sci. Am. Mind 18, 36-43. doi: 10.1038/scientificamericanmind1207-36

Ertl, B., Luttenberger, S., and Paechter, M. (2017). The impact of gender stereotypes on the self-concept of female students in STEM subjects with an underrepresentation of females. Front. Psychol. 8:703. doi: 10.3389/fpsyg.2017.00703

Forsythe, A., and Johnson, S. (2017). Thanks, but no-thanks for the feedback. Assess. Eval. High. Educ. 42, 850-859. doi: 10.1080/02602938.2016.1202190

Freudenthaler, H. H., Spinath, B., and Neubauer, A. (2008). Predicting school achievement in boys and girls. Eur. J. Pers. 22, 231-245. doi: 10.1002/per.678

Harks, B., Rakoczy, K., Hattie, J., Besser, M., and Klieme, E. (2014). The effects of feedback on achievement, interest and self-evaluation: the role of feedback's perceived usefulness. Educ. Psychol. Int. J. Exp. Educ. Psychol. 34, 269-290. doi: 10.1080/01443410.2013.785384

Kamins, M. L., and Dweck, C. (1999). Person versus process praise and criticism: implications for contingent self-worth and coping. Dev. Psychol. 35, 835-847. doi: 10.1037/0012-1649.35.3.835

Lent, R. W., and Brown, S. D. (2019). Social Cognitive Career Theory at 25: empirical status, choice, and performance models. J. Vocat. Behav. 115:103316. doi: 10.1016/j.jvb.2019.06.004

Luttenberger, S., Paechter, M., and Ertl, B. (2019). Self-concept and support experienced in school as key variables for the motivation of women enrolled in STEM subjects with a low and moderate proportion of females. Front. Psychol. 10:1242. doi: 10.3389/fpsyg.2019.0 1242

Luttenberger, S., Wimmer, S., and Paechter, M. (2018). Spotlight on math anxiety. Psychol. Res. Behav. Manag. 11, 311-322. doi: 10.2147/PRBM.S14 1421

\section{AUTHOR CONTRIBUTIONS}

MP, SL, and BE have made a substantial, direct, and intellectual contribution to the work and approved it for publication. All authors contributed to the article and approved the submitted version.

\section{FUNDING}

The authors acknowledge the financial support by the University of Graz.

Mueller, C. M., and Dweck, C. S. (1998). Intelligence praise can undermine motivation and performance. J. Pers. Soc. Psychol. 75, 33-52. doi: 10.1037/0022-3514.75.1.33

OECD (2015). The ABC of Gender Equality in Education: Aptitude, Behaviour, Confidence. Pisa: OECD Publishing. doi: 10.1787/9789264229945-en

She, H. C. (2000). The interplay of a biology teacher's beliefs, teaching practices and gender-based student-teacher classroom interaction. Educ. Res. 42, 100-111. doi: 10.1080/001318800363953

Skipper, Y., and Leman, P. J. (2017). The role of feedback in young people's academic choices. Int. J. Sci. Educ. 39, 453-467. doi: 10.1080/09500693.2017.1294783

Smith, J. L., Lewis, K. L., Hawthorne, L., and Hodges, S. D. (2012). When trying hard isn't natural: women's belonging with and motivation for male-dominated STEM fields as a function of effort expenditure concerns. Pers. Soc. Psychol. Bull. 39, 131-143. doi: 10.1177/0146167212468332

Turner, S. L., Joeng, J. R., Sims, M. D., Dade, S. N., and Reid, M. F. (2019). SES, gender, and STEM career interests, goals, and actions: a test of SCCT. J. Career Assess. 27, 134-150. doi: 10.1177/1069072717748665

Watt, H. M. G., Eccles, J. S., and Durik, A. M. (2006). The leaky mathematics pipeline for girls: a motivational analysis of high school enrolments in Australia and the USA. Equal Opportun. Int. 25, 642-659. doi: 10.1108/02610150610719119

Zeldin, A. L., Britner, S. L., and Pajares, F. (2008). A comparative study of the self-efficacy beliefs of successful men and women in mathematics, science, and technology careers. J. Res. Sci. Teach. 45, 1036-1058. doi: 10.1002/tea.20195

Conflict of Interest: The authors declare that the research was conducted in the absence of any commercial or financial relationships that could be construed as a potential conflict of interest.

Copyright (C) 2020 Paechter, Luttenberger and Ertl. This is an open-access article distributed under the terms of the Creative Commons Attribution License (CC BY). The use, distribution or reproduction in other forums is permitted, provided the original author(s) and the copyright owner(s) are credited and that the original publication in this journal is cited, in accordance with accepted academic practice. No use, distribution or reproduction is permitted which does not comply with these terms. 